\title{
Exchange Rate Dynamics in an Intertemporal General Equilibrium Model with Nominal Rigidities, Imperfect Competition, and Investments.
}

\author{
Allan Bødskov Andersen ${ }^{1}$ \\ Department of Finance \\ The Aarhus School of Business \\ Fuglesangs Allé 4 \\ DK-8210 Aarhus V. \\ Denmark \\ Fax: +45 86151943 \\ Tel: +4589486656 \\ E-mail: aan@hha.dk
}

August 11, 1998

${ }^{1}$ I wish to thank Michael Christensen, Tom Engsted and Neil Rankin for valuable comments. The author alone is responsible for any errors. 


\begin{abstract}
We develop an extension to the Obstfeld and Rogoff $(1995,1996)$ two sector model with imperfect competition and nominal wage rigidities. Contrary to the Obstfeld and Rogoff $(1995,1996)$ analysis, we make an explicit account for the investment side of the two-sector economy. We analyze the implications for the exchange rate's reaction to an unexpected permanent rise in the money supply. The model replicates an overshooting result for certain parameter values. Moreover, we are able to isolate the effect of investments on the exchange rate. The presence of investments causes the exchange rate to overshoot less compared to the situation in Obstfeld and Rogoff $(1995,1996)$, in which labor is the sole factor of production.
\end{abstract}

Keywords: Monopolistic competiton; Nominal rigidities; Exchange rates; Overshooting JEL classification: F31, F41 


\section{Introduction}

Recent research in international finance has stressed the importance of explicit micro foundations in dynamic exchange rate models. Prominent examples include Obstfeld and Rogoff $(1995,1996)$ and Rankin $(1994,1998)$. This approach has primarily emerged as a reaction to the criticisms of the Keynesian-type ad hoc models of the 70's and early 80's which emphasized the importance of nominal rigidities, and the real business cycle (RBC) literature, which has emphasized explicit micro foundations, but in combination with frictionless goods, money, and labour markets.

The approach applied in this paper combines the presence of nominal rigidities with careful accounting for the microeconomic behaviour of individuals and firms. The Obstfeld and Rogoff $(1995,1996)$ analyses further assume that monopolistic competition is a crucial feature of the goods market, and hence they provide a good reason (price is set at a level greater than marginal cost) for output to be demand determined ex post in the short run. Bénassy (1995) incorporates capital accumulation in a closed economy, but introduces the short run nominal rigidity through the otherwise frictionless labour market. Therefore, he lacks a credible explanation for why the labour supply is demand determined ex post in the short run.

The present paper explores the exchange rate dynamics in a small open economy model with investments in an analytically tractable way. We shall further assume, that individuals are represented by monopoly unions, which implies that the wage is set above the marginal disutility of labour, and hence we have a reason for the employment to be demand determined ex post in the presence of nominal wage rigidity.

Before presenting the model, it may be worth elaborating a bit on the rationale for the introduction of investments. Obstfeld and Rogoff (1996) argue that treating the capital stock as being constant is a good approximation when the focus is on short run dynamics, and therefore they disregard investments. While it may be true that the capital stock is approximately constant in the short run, investments are certainly not. Investment is indeed a very volatile macroeconomic variable. Using quarterly data, Baxter and Crucini (1993) reports a standard deviation of investments of $5.52 \%$ for the US over the period 1957:1 - 1986:2, which makes it the most volatile component of real GNP 
(real GNP has a standard deviation of 1.84\%). And more important, judged from the calculations in Baxter and Crucini (1993) these orders of magnitude seem to be fairly robust over developed countries. Hence, leaving out investments would be to miss much of the action. This is especially so when the focus is on welfare analysis. In the Obstfeld and Rogoff (1995) analysis, the welfare implications of their policy experiments depend crucially on the current account dynamics. It holds trivially that the current account equals the difference between savings and investments. Hence, we run the risk of making wrong inference about the current account dynamics (and hence false welfare conclusions) when we ignore the investment side of the economy.

Moreover, investments are almost never bounded by contracts, which is often the case with labour supply in many real world labour market agreements.

It seems that these arguments constitute a good reason for incorporating the investments decision, even when the main interest is short run macro analysis. The model presented in the next sections can therefore be seen as an extension of the Obstfeld and Rogoff (1996) (section 10.4) model. Moreover, the investment side of the economy is close to Bénassy (1995), but the present model incorporates monopolistic competition in the labour market as well as it abstracts from the closed economy assumption. The admittedly simple form of investment which is introduced here ensures analytical tractability, and shows some of the necessary steps involved in incorporating investments in this type of models.

The paper is organized as follows. The basic microeconomic setup is presented in section 2.1, and in section 2.2 the dynamics of the macroeconomic equilibrium is described by log-linear versions of the model's equations. In section 3 the long run implications for the exchange rate are explored under the assumption that all nominal variables are perfectly flexible. In section 4 we analyze the Dornbusch experiment (Dornbusch, 1976), i.e. an unanticipated permanent shock to the money supply, in the case where the nominal wage is fixed for one period. Section 5 concludes. 


\section{The Model}

\subsection{Microeconomic Behaviour}

Obstfeld and Rogoff (1995) assumes that labour is the only factor of production, and this allows them to simplify the production side of the economy considerably. In particular, they can identify the disutility of work with home output. Here we have two factors of production, capital and labour, which imply that the factor markets are to be considered explicitly. Hence, the firms' decision problems are considered in detail.

Now, consider a small open economy with perfect competition in the goods market. There is one traded good, for which there exists a frictionless international market. The home country is endowed with an exogenous amount of the traded good. The home country is specialized in production of a nontraded good, and can convert this good into an (equally non-traded) investment good at zero cost. We shall also abstract from installation costs. Individuals consume both types of goods. Households own domestic capital and make the investment, the consumption and the labour supply decisions. Firms hire the capital at the market real interest rate and determine the labour demand. All profits are redistributed to the households (although perfect competition ensures that profits are zero in equilibrium). There is a single internationally traded real bond denominated in the traded consumption good. This assumption is not restrictive, since we are going to abstract from uncertainty. Money is introduced by the utility of real balances approach ${ }^{1}$. We are not going to present a deeper "micro" explanation for individuals to assign positive utility to real balances, but simply apply it here as a useful short cut. The exchange rate is tied down by the law of one price condition. I acknowledge all the usual criticisms of this exchange rate model, but it is used here because it makes sense in a world with only one traded good and no transportation costs or other impediments to trade, and, of course, it also simplifies the analysis considerably.

\footnotetext{
${ }^{1}$ The utility of real balances approach was first used by Sidrauski (1967). Utility of real balances ensures (contingent on the specific choice of utility function) that there can be some degree of substitution between real balances and other components of the utility function. In that sense the utility of real balances approach is more flexible than introducing money through a Clower constraint.
} 


\subsubsection{The Firms}

A representative firm produces a single, nontraded good by means of capital and a continuum of different labour types indexed by $j \in[0,1]$ supplied by individual households. We can think of each type of labour being represented by a union. Let $l_{t}(j)$ denote the supply of labour of type $j$ at time $t$. The representative firm employs labour according to the CES specification

$$
L_{t}=\left[\int_{0}^{1} l_{t}(j)^{\frac{\theta-1}{\theta}} d j\right]^{\frac{\theta}{\theta-1}},
$$

where $L_{t}$ denotes the (aggregate) level of labour input in the firm. $\theta$ is the wage elasticity of demand for labour that each union faces, and is furthermore the elasticity of substitution between each type of labour in the sub-production function. We assume that the prevailing market conditions on the labour market is well characterized by monopolistic competiton, such that $\theta>1$. The fact that the unions face less than perfect elastic labour demand (which corresponds to the $\theta \rightarrow \infty$ case (i.e. perfect competition)) implies that the union will choose a point on the labour demand curve where the wage elasticity is greater than one, and the real wage is set above the marginal disutility of labour (we shall explore this important feature of the model more thoroughly later). Hence, from the viewpoint of the unions any unemployment is voluntary, and involuntary from the viewpoint of individuals. The firms transform labour and capital into the non-traded good according to the standard CRTS Cobb-Douglas technology with no productivity changes, such that

$$
Y_{N, t}=K_{t}^{\alpha} L_{t}^{1-\alpha}
$$

where $K_{t}$ denotes the capital level at time $t$, and $Y_{N, t}$ is the supply of the non-traded good at time $t$.

Letting $\rho_{t}$ denote the real rental rate of capital (measured in non-tradables) at time $t, P_{N, t}$ the price of the non-traded good at time $t$, and $w_{t}(j)$ the nominal wage for a unit of type $j$ labour, the representative firm solves the profit maximization problem

$$
\max _{l_{t}(j), K_{t}} \Pi=P_{N, t} Y_{N, t}-\int_{0}^{1} w_{t}(j) l_{t}(j) d j-P_{N, t} \rho_{t} K_{t},
$$

subject to (1) and (2). The firms first order condition with respect to labour is then

$$
l_{t}(j)=(1-\alpha)^{\theta}\left(\frac{w(j)}{P_{N, t}}\right)^{-\theta} K_{t}^{\alpha \theta} L_{t}^{1-\alpha \theta} .
$$


Isolating the real wage gives us the inverse labour demand schedule

$$
\frac{w_{t}(j)}{P_{N, t}}=(1-\alpha) l_{t}(j)^{-\frac{1}{\theta}} K_{t}^{\alpha} L_{t}^{\frac{1}{\theta}-\alpha} \quad \forall j .
$$

Note that the real wage in optimum depends on the level of capital, since changes in the capital level changes the marginal product of labour. Furthermore, in the $\theta \rightarrow \infty$ case we get the familiar Cobb-Douglas expression under perfect competition.

The firms first order condition with respect to capital becomes

$$
\rho_{t}=\alpha K_{t}^{\alpha-1} L_{t}^{1-\alpha}
$$

The firms behave competitively so that each factor of production is paid its marginal product in each period.

We furthermore assume that capital depreciates fully after one period ${ }^{2}$, such that

$$
K_{t+1}=I_{t}
$$

where $I_{t}$ is investment at time $t$.

\subsubsection{Individuals and unions}

Since households have monopoly power in the labour market, they take the labour demand (5) into account in their optimization problem. A representative household $j$ maximizes at $t=0$ the following infinite life-time utility function:

$$
\begin{array}{r}
U_{0}^{j}=\sum_{t=0}^{\infty} \beta^{t}\left[\gamma \log C_{T, t}^{j}+(1-\gamma) \log C_{N, t}^{j}+\frac{\chi}{1-\varepsilon}\left(\frac{M_{t}^{j}}{P_{t}}\right)^{1-\varepsilon}-\frac{\kappa}{2} l_{t}(j)^{2}\right] \\
0<\beta<1, \quad 0 \leq \gamma \leq 1,
\end{array}
$$

where $\beta$ is the subjective time preference parameter, $\gamma$ is the relative weight attached to consumption of the traded good, $C_{T, t}^{j}, C_{N, t}^{j}$ is the consumption of the traded and non-traded good by individual $j$, respectively, $M_{t}^{j}$ is individual $j$ 's money holdings at the end of period ${ }^{3} t$, and $P_{t}$ denotes the true price index associated with the specific

\footnotetext{
${ }^{2}$ Bénassy (1995) shows a suitable way to relax this assumption.

${ }^{3}$ In discrete time models with real balances entering the utility function, one has to be careful when defining the timing of this term. The 'end of period real balance' approach applied here ensures that money is neutral per se. However, it has the disadvantage that individuals do not derive utility of real balances within the period they enjoy the transaction services they provide. See Rankin (1994) for further discussion.
} 
parameterization of the utility function employed here, and is given by ${ }^{4}$

$$
P=\frac{P_{T}^{\gamma} P_{N}^{1-\gamma}}{\gamma^{\gamma}(1-\gamma)^{1-\gamma}} .
$$

The log-specification implies that the intertemporal elasticity of substitution equals one and is made purely for analytical convenience. Money enters utility in the more general CRRA specification. $1 / \varepsilon$ is the consumption elasticity of money demand, and turns out to be an important factor as to whether overshooting can occur. The last term reflects the disutility of labour. Note that we can interpret a rise in $\kappa$ as a preference shift towards leisure.

Individuals face an intertemporal budget constraint, which in nominal terms is

$$
\begin{aligned}
P_{T, t} B_{t+1}^{j}+M_{t}^{j}=P_{T, t}(1+r) B_{t}^{j}+ & M_{t-1}^{j}+P_{N, t} \rho_{t} I_{t-1}+w_{t}(j) l_{t}(j)+P_{T, t} \bar{y}_{T} \\
& -P_{N, t} C_{N, t}^{j}-P_{T, t} C_{T, t}^{j}-P_{N, t} I_{t}-P_{T, t} \tau_{t},
\end{aligned}
$$

where $B_{t+1}^{j}$ is individual $j$ 's holding of real bonds (denominated in tradables) at the beginning of period $t+1, r$ is the constant world real interest rate faced by the small domestic country, and $\tau_{t}$ is a lump sum tax (or transfer if negative), also denominated in tradables.

The real bond is the only internationally traded asset. It has a face value of one, and it pays the owner one plus the real interest rate next period. We can think of the bonds as being issued by the private households.

The interpretation of the budget constraint as follows. The left hand side is the saving of individual $j$ at the beginning of period $t+1$. This saving equals the difference between the savings at the beginning of period $t$ plus the income (labour income, rental income, interest income from issuing bonds, and the (constant) endowment of the traded good, $\bar{y}_{T}$ ) individual $j$ obtains during period $t$, minus that period's total absorpsion (consumption, investment, and net taxes).

We can rewrite the budget constraint in order to explore how the current account dynamics is determined in the model. The current account is by definition given by the change in net foreign assets, such that from (10) we get (assuming symmetric individuals,

\footnotetext{
${ }^{4}$ Technically, $P$ is defined as the minimum expenditure needed in order to buy one unit of the consumption index defined by $C_{T}^{\gamma} C_{N}^{1-\gamma}$.
} 
so we can drop the superscript $j$ )

$$
C A \equiv B_{t+1}-B_{t}=\underbrace{\underbrace{B_{t}+\frac{P_{N, t}}{P_{T, t}} \rho_{t} I_{t-1}+\frac{w_{t}}{P_{T, t}} L_{t}+\bar{y}_{T}}_{\text {income }}-\underbrace{\frac{P_{N, t}}{P_{T, t}} C_{N, t}-C_{T, t}}_{\text {consumption }}}_{\text {saving }}-\underbrace{\frac{P_{N, t}}{P_{T, t}} I_{t}}_{\text {investment }}
$$

As expected, we end up with the identity that the current account equals saving less investment.

The government issues money and finances $\tau_{t}$ purely out of seignorage, such that the government budget constraint becomes (assuming zero government spending ${ }^{5}$ )

$$
\tau_{t}+\frac{M_{t}-M_{t-1}}{P_{T, t}}=0
$$

Without loss of generality, we will assume that the government balances its budget each period.

The representative household's first order conditions can be derived by maximizing (8) subject to the labour demand (5) and the budget constraint ${ }^{6}(10)$. Since the unions are all small compared to the market, it is natural to assume that the unions cannot affect any aggregate variables. In particular, we will assume that the unions take $L_{t}$ and $K_{t}$ as given.

The first order conditions are

$$
\begin{gathered}
C_{T, t+1}^{j}=\beta(1+r) C_{T, t}^{j}, \\
\frac{\gamma}{C_{T, t}^{j}}=\chi \frac{P_{T, t}}{P_{t}}\left(\frac{M_{t}^{j}}{P_{t}}\right)^{-\varepsilon}+\beta \frac{P_{T, t}}{P_{T, t+1}}\left(\frac{\gamma}{C_{T, t+1}^{j}}\right) \\
l_{t}(j)^{1+\frac{1}{\theta}}=\frac{\gamma}{C_{T, t}^{j} \kappa} \frac{P_{N, t}}{P_{T, t}}\left[(1-\alpha)\left(1-\frac{1}{\theta}\right) I_{t-1}^{\alpha} L_{t}^{\frac{1}{\theta}-\alpha}\right] \\
\frac{\beta}{C_{T, t+1}^{j}}\left(\frac{P_{N, t+1}}{P_{T, t+1}}\right)\left[\rho_{t+1}+(1-\alpha) \alpha I_{t}^{\alpha-1} l_{t+1}(j)^{1-\frac{1}{\theta}} L_{t+1}^{\frac{1}{\theta}-\alpha}\right]=\left(\frac{P_{N, t}}{P_{T, t}}\right) \frac{1}{C_{T, t}^{j}} \\
C_{N, t}^{j}=\frac{1-\gamma}{\gamma}\left(\frac{P_{T, t}}{P_{N, t}}\right) C_{T, t}^{j}, \quad \forall j .
\end{gathered}
$$

\footnotetext{
${ }^{5}$ It is possible to relax this assumption without changing any of the subsequent results

${ }^{6}$ One way to solve this is to divide (10) with $P_{T, t}$. Then insert (5) in the resulting expression, isolate $C_{T, t}^{j}$ and substitute this into (8). Solve this now unrestricted maximization problem with respect to the choice variables $C_{N, t}^{j}, B_{t+1}^{j}, M_{t}^{j}, l_{t}(j)$ and $I_{t}$.
} 
Equilibrium also requires the transversality condition that ${ }^{7}$

$$
\lim _{S \rightarrow \infty}\left(\frac{1}{1+r}\right)^{S}\left[B_{t+S+1}^{j}+\frac{M_{t+S}^{j}}{P_{T, t+S}}\right]=0, \quad \forall j,
$$

which rules out speculative bubbles in equilibrium.

The interpretation of these conditions goes as follows. (13) is the dynamic consumption Euler condition which arises when the flow utility function is additively separable. It governs the optimal allocation of traded good consumption between periods. If we impose the steady state equilibrium condition that

$$
r=\frac{1-\beta}{\beta},
$$

i.e. we rule out consumption tilting, then individuals are able to perfectly smooth traded good consumption independently of non-traded good consumption. This would not hold if the marginal utility of consumption of traded goods depended on the consumption of the non-traded good and vica versa. At a first glance, it is hard to think of any a priori reasons (apart from a pure coincidence) why (19) should hold. However, in a world with many individuals, and hence many different $\beta$ 's, the 'most patient' individuals eventually end up by driving out all the others. Thus, (19) is a reasonable condition in the steady state equilibrium.

(14) is household $j$ 's demand for real balances. In its derivation we have used (13), and one could make it dependent on the nominal interest rate by applying the Fisher Parity,

$$
1+R_{t+1}=\frac{P_{T, t+1}}{P_{T, t}}(1+r)
$$

where $R_{t+1}$ denotes the nominal interest rate from time $t$ to $t+1$.

The money demand equation says that in equilibrium, households must be indifferent between consuming one extra unit of the consumption good at time $t$, or raising cash balances with the corresponding amount and enjoy the derived utility from transaction services and convert the cash balance back to the consumption good at time $t+1$.

(15) is the equilibrium consumption-leisure trade off. The supplied amount of labour depends negatively on consumption since the higher the household consumption the bet-

\footnotetext{
${ }^{7}$ The transversality condition can be derived by iterating the household's flow budget constraint (10).
} 
ter the agents are off, and hence they choose to consume more leisure. It depends positively on investments because a higher capital stock makes the labour force more productive and hence raises the equilibrium wage. The assumption of monopolistic competition comes into play here, which we can illustrate as follows. Due to their monopoly power agents (unions) took the firms demand for labour (5) into account in their optimization problems. Unions recognize that an extra unit of labour supplied causes the equilibrium real wage to fall a little, not only on the last (marginal) unit supplied, but also on all previously supplied units of labour. Thus, the marginal effect on the real wage of an marginal change in labour supply is greater under monopolistic competition than under perfect competition. We can illustrate this by substituting the expression for the real wage (5) into (15) and rearrange to get

$$
l_{t}(j)=\frac{\gamma}{C_{T, t} \kappa}\left(\frac{P_{N, t}}{P_{T, t}}\right)\left[\left(1-\frac{1}{\theta}\right) \frac{w_{t}(j)}{P_{N, t}}\right] .
$$

The effect stemming from monopoly power is represented by the $\theta$-term. Recalling that $\theta>1$, it is immediate that labour supply (and hence equilibrium output; see section 3) is inefficiently low. As monopoly power decreases $(\theta \rightarrow \infty)$ employment tends to the efficient level which would prevail under perfect competition ${ }^{8}$. Furthermore, the exact same algebra reveals that the real product wage is set above the marginal disutility of labour, and constitutes our argument that with preset wages (which we will assume later) employment becomes demand determined, since individuals facing a small demand shock will be willing to supply the extra amount of labour ex post. This is illustrated in Figure 1. The labour supply schedule under monopolistic competition $S^{\prime}$ is everywhere above the relevant schedule under perfect competition, $S$. The demand for labour is illustrated by the $D$ schedule. With unions having market power, employment and real wage are given by $L^{\prime}$ and $\left(W / P_{N}\right)^{\prime}$, respectively. Thus, the labour supply in equilibrium is set below its efficient perfect competition-level $(L)$, and the real wage is similarly set above the efficient level, which is $W / P_{N}$. Moreover, with monopolistic competition the real wage is set above the marginal disutility of labour, which is given by $\left(W / P_{N}\right)^{\prime \prime}$ in the figure. The analytical counterparts are $\left(W / P_{N}\right)^{\prime}=a\left(1-\frac{1}{\theta}\right)^{\frac{\alpha}{1+\alpha}}$ and $L_{t}^{\prime}=b\left(\left(1-\frac{1}{\theta}\right)^{\frac{-\alpha}{1+\alpha}}\right.$,

\footnotetext{
${ }^{8}$ It is fairly easy to show that under perfect competition the supply of labour (which in this case equals the marginal disutility of labour) will be $l_{t}(j)=\frac{\gamma}{C_{T, t} \kappa}\left(\frac{w_{t}(j)}{P_{T, t}}\right)$.
} 
where $a$ and $b$ are unimportant constants depending on the structural parameters. These expressions confirm the intuition given above: as $\theta \rightarrow \infty$ we end up in the efficient perfect competition solution.

We can now also illustrate the fact that the equlibrium labour supply becomes demand determined when the wage is rigid. Let us assume that the wage is constant at the $\left(W / P_{N}\right)^{\prime}$ level and that there is a shock to the labour demand, such that this shifts to the $D^{*}$. The new level of employment now becomes $L^{*}$ and is indeed demand determined. However, if the demand shock is large and shifts to, say, $D^{* *}$, the employment level becomes $L^{* *}$ which is supply determined even in the presence of preset prices.

The next first order condition (16) governs the optimal allocation of consumption and investment. The exact nature of this condition depends crucially on the exact assumptions regarding the endogeniety of investments from the viewpoint of the firms, individuals, and unions, respectively. The distinction between individuals and unions has not been important up to this point. However, the slightly skizofrenic nature of the economy needs to be considered in more detail here. Most realistic, one would like to assume that the only thing that is endogenous from the viewpoint of the unions is the real product wage, such that unions take the capital level as given. With this assumption, condition (16) is simplified to

$$
\left(\frac{P_{N, t}}{P_{T, t}}\right) \frac{1}{C_{T, t}^{j}}=\frac{\beta}{C_{T, t+1}^{j}}\left(\frac{P_{N, t+1}}{P_{T, t+1}}\right) \rho_{t+1},
$$

which upon application of the consumption Euler equation is reduced to the familiar arbitrage condition

$$
\left(\frac{P_{N, t}}{P_{T, t}}\right)(1+r)=\left(\frac{P_{N, t+1}}{P_{T, t+1}}\right) \rho_{t+1},
$$

where the relative price terms enter because $1+r$ is measured in tradables, while the real rental rate is measured in non-tradables. Furthermore, if we at time $t$ expect the relative price of non-tradables to rise at time $t+1$, individuals will rationally choose to invest more today when the price of the investment good is low. However, higher investment today imply a higher capital stock tommorow, why $\rho_{t+1}$ is lower, ceteris paribus.

While it is perfectly possible to argue that this is the most reasonable setup, we can extract further insights by assuming that unions are effectively identical to individuals. Since individuals own the firms, it may not be unreasonable to think that they do control 


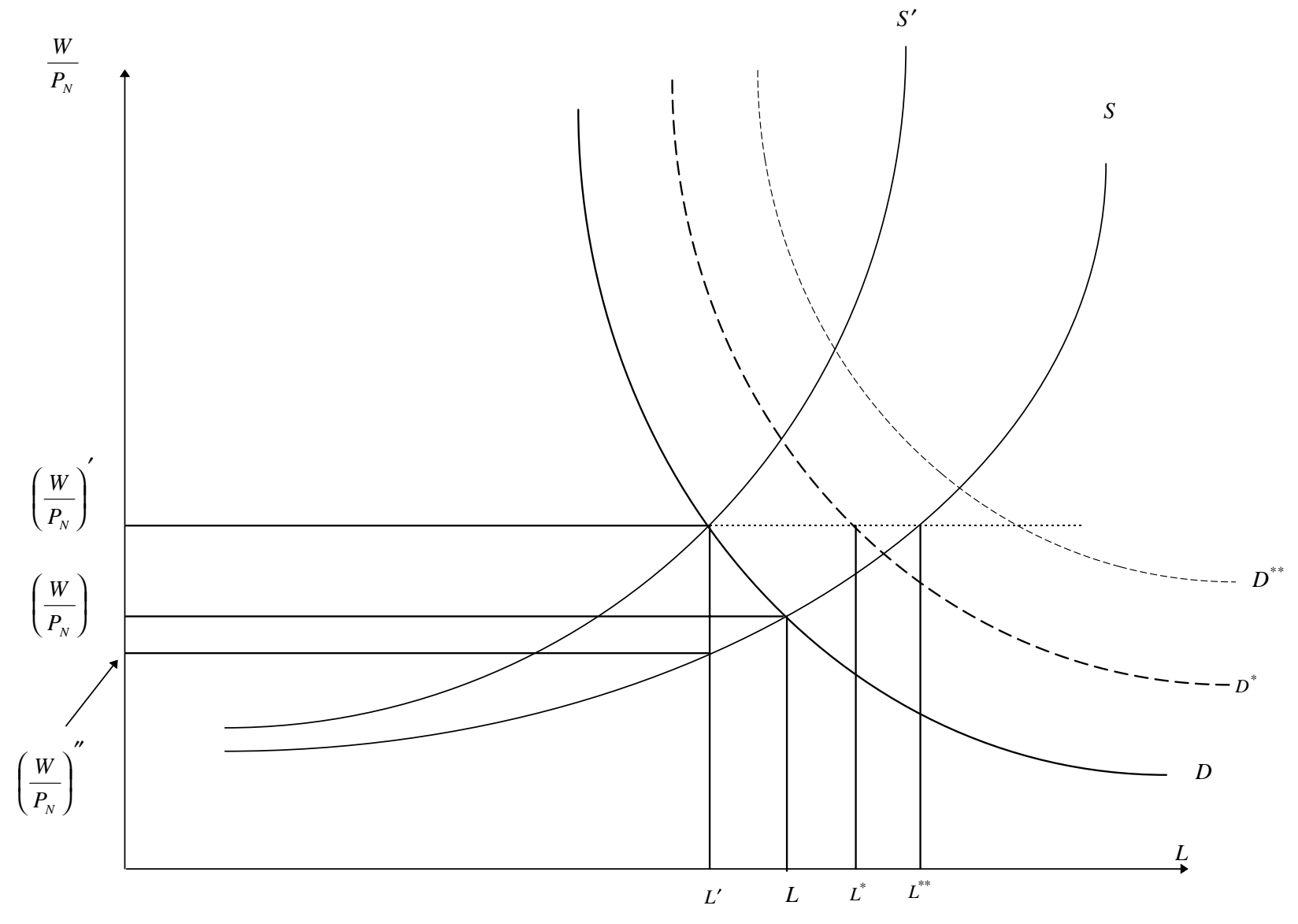

Figure 1: The Labour Market 
the investment level, and hence take into account that a higher capital stock raises the marginal productivity of labour. Thus, individuals realize that an extra unit of capital not only gives the real rental rate in return, but also a higher real wage. This setup leads to condition (16), in which the extra term relative to (21) exactly reflects the marginal effect on the wage of an extra unit of capital. Now, assume that all individuals are symmetric, such that they all ask the same wage, supply the same amount of labour etc. in equilibrium, then from (1) we have that $L_{t}=l_{t}(j), \forall j$. Thus, using this and applying the consumption Euler condition on (16) we get the modified 'arbitrage' condition

$$
\left(\frac{P_{N, t}}{P_{T, t}}\right) \frac{1+r}{2-\alpha}=\left(\frac{P_{N, t+1}}{P_{T, t+1}}\right) \rho_{t+1} .
$$

Hence, only when $\alpha \rightarrow 1$, i.e. when production becomes increasingly capital intensive, we obtain (22) in equilibrium. When $0 \leq \alpha<1$, the real return on investments is lower than the risk free rate, exactly because of the wage effect.

The economic interpretation of (16) is as follows. In equilibrium agents are indifferent between consuming one extra unit of consumption at time $t$, or investing that extra unit at time $t$ and enjoying the derived extra utility from converting the extra income from the investment back to the consumption good at time $t+1$. This income depends on the specific assumption about what the unions take as given, as discussed above ${ }^{9}$.

The last first order condition (17) governs the optimal allocation between the traded and the non-traded good. Absent any price fluctuations, traded good consumption is a constant fraction of non-traded good consumption. If the relative price of the traded good increases, households will choose to consume relatively more of the non-traded good. This result is due to the additive separability of the flow utility function, and would not hold in more general specifications.

Finally, the exchange rate is tied down by the law of one price

$$
P_{T, t}=E_{t} P_{T, t}^{*}
$$

where $E_{t}$ is the nominal exchange rate defined as the price of one unit of foreign currency in terms of the domestic currency, and $P_{T, t}^{*}$ is the (exogenous) foreign currency price of

\footnotetext{
${ }^{9}$ Fortunately, whether we choose one or the other specification has no consequence for the later results. This is so because we are going to log-linearize the model and only analyze small changes from the steady state, and the log-linearized versions of (22) and (23) are identical.
} 
the tradable consumption good. Thus, we can simply identify the exchange rate with $P_{T, t}$.

\subsection{Macroeconomic Dynamics}

We now turn to the description of the macroeconomic equilibrium. Solving the model is very hard indeed, since it is dynamic and highly non-linear. We therefore restrict ourselves to analyze (infinitely) small changes from the steady state; in doing so we loglinearize the model around a steady state equilibrium in which all exogenous variables are assumed to be constant. This will also allow the introduction of a more compact notation adopted from Obstfeld and Rogoff (1995).

\subsubsection{The Steady State}

As we have already shown, monopolistic competition causes the labour supply to be inefficiently low. Similar calculations show that home output in the steady state is given by $^{10}$

$$
\bar{Y}_{N, t}=(1+r)^{\frac{2 \alpha}{\alpha-1}} \alpha^{\frac{2 \alpha}{\alpha-1}} \frac{\gamma}{\bar{y}_{t} \kappa}(1-\alpha)\left[1-\frac{1}{\theta}\right] .
$$

As expected the equilibrium output is inefficiently low due to the monopoly power. As $\theta \rightarrow \infty$ the economy tends to the efficient output level that would prevail under perfect competition. Similar algebra leads to the steady state values of the models remaining endogenous variables.

\subsubsection{Log-linearizing Around the Steady State}

Define lower-case letters with a 'hat' to be the log-deviation, or percentage change, from the steady state of the corresponding letters without 'hats', such that for any variable $X_{t}$ : $\hat{x}_{t}=d \log X_{t}=\left(X_{t}-\bar{X}\right) / \bar{X}$, where $\bar{X}$ indicates the steady state value of $X$. All equations in this model are exact log-linear, so the linearizations are relatively straight forward. We shall also focus on a symmetric equilibrium, and therefore drop the superscript $j$ henceforth.

\footnotetext{
${ }^{10}$ In the derivation we have assumed symmetric individuals. The result follows from the firms first order condition with respect to capital (6), employment schedule (20), and the production function (2).
} 
Linearizing the consumption Euler condition (13) we get

$$
\hat{c}_{T, t}=\hat{c}_{T, t+1}=0,
$$

where the last equation stems from ruling out consumption tilting, i.e. assuming that condition (19) is fulfilled.

The money demand equation (14) gives us

$$
\varepsilon\left(\hat{m}_{t}-\hat{p}_{t}\right)=\hat{p}_{T, t}-\hat{p}_{t}+\frac{\beta}{1-\beta}\left(\hat{p}_{T, t}-\hat{p}_{T, t+1}\right) .
$$

The consumption-leisure trade off (15) becomes

$$
\hat{l}_{t}=-\frac{1}{\alpha+1}\left(\hat{p}_{N, t}-\hat{p}_{T, t}\right)+\frac{\alpha}{\alpha+1} \hat{i}_{t-1} .
$$

From condition (16) we get that

$$
\hat{\rho}_{t+1}=\left(\hat{p}_{N, t}-\hat{p}_{T, t}\right)-\left(\hat{p}_{N, t+1}-\hat{p}_{T, t+1}\right) .
$$

Linearizing the consumption allocation condition (17) gives us

$$
\hat{c}_{N, t}=\hat{p}_{T, t}-\hat{p}_{N, t},
$$

where we have used (26).

The firms first order conditions (5) and (6) take the log-linear form

$$
\hat{w}_{t}-\hat{p}_{N, t}=\alpha \hat{i}_{t-1}-\alpha \hat{l}_{t}
$$

and

$$
\hat{\rho}_{t+1}=(1-\alpha) \hat{l}_{t+1}+(\alpha-1) \hat{i}_{t} .
$$

The last pair of equations we need to linearize are the price index (9) and the law of one price condition (24). The linearized versions are

$$
\begin{gathered}
\hat{p}_{t}=\gamma \hat{p}_{T, t}+(1-\gamma) \hat{p}_{N, t}, \\
\hat{p}_{T, t}=\hat{e}_{t}+\hat{p}_{T, t}^{*}=\hat{e}_{t}
\end{gathered}
$$

where the last equation holds because the foreign country's price level is exogenous by assumption. 
The last thing to note before we start manipulating these equations is that (26)(34) apply for any $t$, and, in particular, they also hold once the economy has reached a new steady state. Letting a 'bar' indicate steady state changes, we have for any variable $X: \hat{\bar{x}}=\left(\bar{X}_{1}-\bar{X}_{0}\right) / \bar{X}_{0}$, where subscript zero denotes the initial pre-shock steady state. Thus, 'barred' versions of (26) - (34) are also valid. This means that we are now able to simplify the notation somewhat. Absent any adjustment costs, the economy will reach a new steady state in just one period when reacting to a shock (see appendix A for a proof of this proposition). Therefore, we can identify the values of the variables in (26)- (34) from time $t+1$ and onwards with their steady state values, i.e. the 'barred' versions. Thus, we can drop all time subscripts and let lower case letters denote the short run (period $t$ ) changes, and let 'barred' lower case letters denote the long run (period $t+1$ and onwards) steady state changes.

\section{The Long Run: Flexible Wages and Prices}

Despite the rather complex structure of the model, it yields remarkably simple and intuitive results for the case where no nominal rigidities are present.

We assume that initially there is zero net foreign assets, hence, since the endowment of the traded good is exogenous, we must have that the market clearing condition $C_{T, t}=\bar{y}_{T}$ holds for all $t$. This market clearing condition together with the fact that individuals perfectly smooth traded good consumption, imply that absent any productivity shocks to the traded goods sector, there is no current account dynamics at all, regardless of shocks to the non-traded good sector or money supply. Therefore, there can be no wealth effects stemming from current account surplus or deficit. With flexible prices and wages we further have that money is neutral (this 'classical dichotomy' property follows from the proof given in appendix A). In particular, this implies that in the long run, $\hat{\bar{c}}_{N}=0$. Inserting this in (30) and we get $\hat{\bar{p}}_{T}=\hat{\bar{p}}_{N}$, i.e. the prices for the traded and non-traded good move proportionately. Using this result in the 'barred' version of (33) yields

$$
\hat{\bar{p}}=\hat{\bar{p}}_{T}
$$

If we use this result in the long run version of (27), we see that the steady change in the 
demand for real balances is zero. Hence, in setting the long run money demand equal to the long run money supply (which is $\hat{\bar{m}}-\hat{\bar{p}}$ ), we see that the money market clearing condition becomes

$$
\hat{\bar{m}}=\hat{\bar{p}} \text {. }
$$

Hence, when prices and wages are flexible, a permanent money supply shock does nothing but raise the aggregate price level. In a sense this just confirms our previous results. Combine (36) with the long run version of the law of one price condition (34) and (35), and we get the solution for the long run exchange rate

$$
\hat{\bar{e}}=\hat{\bar{p}}_{T}=\hat{\bar{m}} .
$$

This is all quite intuitive and obeys the standard result of classical dichotomy in monetary economics. Absent any impediments to trade, the induced price effect of a money shock causes the exchange rate to depreciate proportionately through the law of one price, leaving all real variables unaltered. This is the benchmark result against which we will evaluate the results for the short run dynamics in the next section.

A critical assumption behind the solution (37) is that there are no current account dynamics, and hence, no international wealth transfers. This allows us to conclude that money is neutral in the long run, and gives us the necessary implications for the price levels when there are permanent changes in the money supply. The result would not hold if the size of the traded sector were endogenous as in Obstfeld and Rogoff (1995).

\section{The Short Run: Nominal Wage Rigidity}

We will analyze how the economic system reacts to the Dornbusch experiment, namely an unanticipated permanent rise in the money supply, in the presence of nominal wage rigidity. In the present context this policy experiment implies that $\hat{m}=\hat{\bar{m}}$.

We are going to assume that nominal wage rigidity is the central source of monetary non-neutrality. The nominal wage rigidity is modeled in a very crude way, since we simply assume that the nominal wage is fixed for one period. We could think of this as representing one-period wage contracts. Mathematically, this implies $\hat{w}=0$. Moreover, the definition of $\hat{i}$ implies that $\hat{i}=0$. The argument goes as follows. First, note that (29) 
implies that $\hat{\bar{\rho}}=0$. Use this result in the log-version of the firms first order condition with respect to capital to deduce that $\hat{\bar{l}}=\hat{i}$. However, long neutrality of money implies that $\hat{\bar{l}}=0$. Hence, there can be no investment dynamics, neither in the short run, nor in the long run (but the presence of investments will still affect the short run exchange rate dynamics, as will soon become clear). If we allowed for rigidities lasting more than one period (i.e. 'staggering'), this result would not hold. In the present context, agents will rationally foresee that after one period everything is unaltered in real terms.

However, the short run employment level will respond to the money shock in the short run. The assumption of monopolistic competition in the labour market ensures that the real wage is set above the marginal disutility of labour. Thus, the employment level becomes demand determined in the short run, i.e. the labour supply condition (28) is not binding.

In deriving the analytical expression for the exchange rate dynamics, start by noting that with fixed wages, the labour demand is given by [from (31)]

$$
\hat{p}_{N}=\alpha \hat{l}
$$

Insert this in the short run version of (32) and isolate $\hat{\rho}$ and use the resulting expression in the short run version of $(29)$ to get

$$
\hat{p}_{N}=\alpha \hat{p}_{T}
$$

This implies that the short run aggregate price level can be expressed as

$$
\hat{p}=[\gamma+(1-\gamma) \alpha] \hat{p}_{T}
$$

Finally, use the long run money neutrality result from the last section to deduce that $\hat{\bar{p}}_{T}=\hat{\bar{m}}=\hat{m}$, where the last equality holds, because the change in the money supply is permanent. Insert this, (39), and (40) in the money demand equation (27) and rearrange to get our final result for the exchange rate dynamics

$$
\hat{e}=\hat{p}_{T}=\frac{\beta+(1-\beta) \varepsilon}{\beta+(1-\beta)[(\gamma+(1-\gamma) \alpha)(\varepsilon-1)+1]} \hat{m},
$$

where the first equation is due to the law of one price. 


\subsection{Overshooting Revisited}

In comparison with the long run solution (where $\hat{\bar{e}}=\hat{\bar{m}}=\hat{m}$ ) we observe that the model replicates the overshooting ${ }^{11}$ result $(\hat{e}>\hat{m})$ if $\varepsilon>1$. Moreover, if we set $\alpha=0$, i.e. letting labour be the sole factor production as in Obstfeld and Rogoff (1996) (section 10.4), we get as a special case their solution for the exchange rate. Hence, the $\alpha$-term reflects the extra effect stemming from the presence of investments. (41) shows that investments cause the intrinsic exchange rate overshooting to be less compared to the $\alpha=0$ case. When $\alpha \rightarrow 1$, such that production becomes increasingly capital intensive, the overshooting disappears, since the market imperfection and wage stickyness on the labour market effectively leaves the model.

What is the intuition behind this result? Suppose initially that $\alpha=0$, which implies that the wage rigidity translates directly into non-traded consumption good price rigidity [see equation (39)]. The reason for this is the following. When $\alpha=0$, technology exhibits CRTS with respect to labour, such that firms can change their production scedule without changing marginal costs, i.e. the labour demand is perfectly elastic. Consequently, the assumption of perfect competition assures that the firms cannot raise the price of the non-traded good, when they face an increased demand.

Now, recall that $1 / \varepsilon$ is the consumption elasticity of money demand in this model. Suppose that $\hat{p}_{T}$ increased in proportion to $\hat{m}$, then (since $\hat{p}_{N}$ is zero) the supply of real balances would rise by less, namely $(1-\gamma)$ times that amount. With $\alpha$ set to zero, a one percent rise in $\hat{p}_{T}$ causes an equiproportionate increase in $\hat{c}_{N}$, which in turn corresponds to a $(1-\gamma)$ percent increase in real consumption, $C$. Hence, if $\varepsilon>1$, the demand for real balances rises by less than $(1-\gamma)$. Therefore, $\hat{p}_{T}$ must rise by more in order to clear the money market and, by the law of one price, the exchange rate must overshoot.

Now, consider $0<\alpha<1$. In this case $\hat{p}_{N}$ will change by $\alpha \hat{l}$ because with the fixed factor of production (investments) we have DRTS with respect to labour. Therefore the labour demand is less that perfectly elastic, reflecting increasing marginal costs of production in the short run. Hence, firms are able to change the price of the non-traded

\footnotetext{
${ }^{11}$ Here the term 'overshooting' means that the short run exchange rate level is greater than its long run level.
} 
good in reaction to demand shocks.

The price index is given by $\hat{p}=\left[(\gamma+(1-\gamma) \alpha] \hat{p}_{T}\right.$. Again, if $\hat{p}_{T}$ were to rise in proportion to $\hat{m}$ then, by the price index, the supply of real balances would rise by $1-[\gamma+(1-\gamma) \alpha]$ $[=(1-\gamma)(1-\alpha)]$, i.e. by less than before.

Since $\hat{c}_{N}=(1-\alpha) \hat{p}_{T}$, real consumption expands by $(1-\gamma)(1-\alpha) \hat{p}_{T}$. Again, demand for money will be less than supply for money, and the exchange rate must overshoot in order to clear the money market. But the initial change is closer to the long run change in the money supply $(=0)$, and hence the exchange rate overshoots by less than in the $\alpha=0$ case.

The $N$-good sector expands less when $0<\alpha<1$, since the marginal product of labour decreases faster than the $\alpha=0$ case. Hence, the distortion created by the fixed wage is less than when labour is the sole factor of production.

\subsection{Welfare implications}

Lastly, a note on the welfare implications of the model. Welfare must unambigously increase due to the unexpected rise in the money-supply. This follows directly from inspecting the utility function. During the period in which the monetary expansion takes place, the consumption of the non-traded good increases, and real balances increases. However, the amount of supplied labour also increases, which counts negatively in the utility. But the real wage was initially set above the marginal disutility of labour, hence, the mere fact that unions choose to supply the extra amount of labour reflects that it is optimal to do so. Therefore, lifetime utility must increase due to the Dornbusch experiment.

It is important to note that these results all depends crucially on the assumption that the monetary expansion is unexpected (it is even exogenous here). There is no scope for any systematic welfare increases by means of monetary policy. Anticipated changes in the money supply cannot alter the real economy in any way. If monetary policy were determined endogenously as in the seminal paper by Barro and Gordon (1983), pricesetters (firms) will take this fact into account in forming their price expectations, and game-theoretic tools can be applied to analyze equilibrium in this case. The present 
model can be thought of as providing a microfoundation for these ad hoc models.

\section{Conclusion}

The model shows that the mere presence of investments, or more generally, any fixed factor of production can have important implications for the short run exchange rate dynamics, even in the, admittedly, very simple case considered here. Disregarding investments may be disregarding potentially important economic channels, even when the scope is short run macroeconomic dynamics.

The advantages of the explicit microfoundation are obvious in the model. We have a far more comprehensive knowledge about the underlying economic structure that generates the overshooting result, than we have in a, say, Dornbusch-type framework. Most important, we know it is optimal for the exchange rate to overshoot. Furthermore, we are able to make a credible statement about the welfare properties of the model.

Several interesting extensions of the model can be identified. Relaxing the assumptions of zero productivity gains and zero government spending are obvious candidates for introducing real shocks. Moreover, extending the model to allow for multiperiod wage or price rigidity would bring more interesting action into the investment decision. Endogenizing the traded good sector would also bring current account dynamics into play. These topics are, however, left for further research. 


\section{References}

Barro, Robert J. and David B. Gordon (1983), 'Rules, discretion and reputation in a model of monetary policy', Journal of Political Economy 91, 101-121.

Baxter, Marianne and Mario J. Crucini (1993), 'Explaining savings-investment correlations', The American Economic Review 83, 416-436.

Bénassy, Jean-Pascal (1995), 'Money and wage contracts in an optimizing model of the business cycle', Journal of Monetary Economics 35, 303-315.

Blanchard, Olivier J. and Nobuhiro Kiyotaki (1987), 'Monopolistic competition and the effects of aggregate demand', American Economic Review 77, 647-666.

Blanchard, Olivier J. and Stanley Fischer (1989), Lectures on Macroeconomics, The MIT Press, Cambridge, MA.

Dixon, Huw D. (1995), Imperfect competition and open economy macroeconomics, in F.van der Ploeg, ed., 'The Handbook of International Macroeconomics', Blackwell Publishers, Oxford, UK.

Dornbusch, Rudiger (1976), 'Expectations and exchange rate dynamics', Journal of Political Economy 84, 1161-1176.

Obstfeld, Maurice and Alan C. Stockman (1985), Exchange rate dynamics, in R.Jones and P.Kenen, eds, 'Handbook of International Economics', Elsevier Science Publishers B.V.

Obstfeld, Maurice and Kenneth Rogoff (1995), 'Exchange rate dynamics redux', Journal of Political Economy 103, 624-660.

Obstfeld, Maurice and Kenneth Rogoff (1996), Foundations of International Macroeconomics, The MIT Press.

Rankin, Neil (1994), 'Monetary uncertainty in discrete-time utility-of-money models', Economics Letters 44, 127-132. 
Rankin, Neil (1995), Quantity-constrained models of open economies, in F.van der Ploeg, ed., 'The Handbook of International Macroeconomics', Blackwell Publishers, Oxford, UK.

Rankin, Neil (1998), 'Nominal rigidity and monetary uncertainty in a small open economy', Journal of Economic Dynamics and Control, forthcoming .

Sidrauski, M. (1967), 'Rational choice and patterns of growth in a monetary economy', The American Economic Review 57, 534-544. 


\section{Appendix A}

We will sketch a proof of the proposition that under flexible prices and wages the 'real' part of the economy must always be in a steady state.

Assuming symmetric individials, we have the following real-sector equations which hold for all $t$ under flexible prices, and which are 'static'. For the firms we have

$$
\frac{W_{t}}{P_{N, t}}=(1-\alpha) K_{t}^{\alpha} L_{t}^{-\alpha}
$$

and

$$
\rho_{t}=\alpha K_{t}^{\alpha-1} L_{t}^{1-\alpha}
$$

From the firm's zero profit condition we reach

$$
Y_{N, t}=\frac{W_{t}}{P_{N, t}} L_{t}+\rho_{t} K_{t}
$$

From the households first order conditions we have (ruling out consumption tilting and imposing traded goods market clearing (i.e. assuming zero net foreign assets))

$$
\begin{gathered}
C_{T, t+1}=C_{T, t}=\bar{y}_{T}, \quad \forall t \\
L_{t}^{1+\alpha}=\frac{\gamma}{C_{T, t} \kappa}\left(\frac{P_{N, t}}{P_{T, t}}\right)\left[(1-\alpha)\left(1-\frac{1}{\theta}\right) K_{t}^{\alpha}\right], \\
C_{N, t}=\frac{1-\gamma}{\gamma}\left(\frac{P_{T, t}}{P_{N, t}}\right) C_{T, t} .
\end{gathered}
$$

Hence, from (45) we see that with zero net foreign assets there can be no current account dynamics at all, since the market for tradables always clears in the home country.

From the individuals flow budget constraint we get another real-sector equation. Use the government budget constraint to eliminate the $M$ and $\tau$ terms from the budget constraint, impose the conditions $B_{t+1}=0$ and traded goods market clearing to reach

$$
\left(\frac{P_{N, t}}{P_{T, t}}\right) \rho_{t} K_{t}+\frac{W_{t}}{P_{N, t}} L_{t}=\left(\frac{P_{N, t}}{P_{T, t}}\right) C_{N, t}+\left(\frac{P_{N, t}}{P_{T, t}}\right) I_{t}
$$

Lastly, the market clearing condition for the non-traded goods is

$$
Y_{N, t}=C_{N, t}+I_{t}
$$


Thus, we now have 9 unknowns $\left(\frac{W_{t}}{P_{N, t}}, L_{t}, \rho_{t}, C_{N, t}, C_{T, t}, \frac{P_{N, t}}{P_{T, t}}, Y_{N, t}, K_{t}\right.$, and $\left.I_{t}\right)$ and 9 equations $[(42)-(49)$ and the production function (2)]. Hence, we have a timeindependent system, whose solution must be equally time-independent. Therefore, with no nominal rigidities, the real economy must always be in a steady state. 